\title{
Knowledge and Implementation of the S3 Guideline on Gestational Diabetes among Gynecologists and Diabetologists Four Years after Publication Results of a Survey of 773 Gynecologists and 76 Diabetologists on their Knowledge of the Guideline on Gestational Diabetes (AWMF 057-008, 2011) \\ Kenntnis und Umsetzung der S3-Leitlinie zum Gestationsdiabetes - bei Gynäkologen und Diabetologen 4 Jahre nach Veröffentlichung Ergebnisse einer Befragung von 773 Gynäkologen und 76 Diabetologen zur Kenntnis der Leitlinie zum Gestationsdiabetes (AWMF 057-008, 2011)
}

Authors

Affiliations
T. Groten $^{1 *}$, S. Schmitz ${ }^{2 *}$, C. Schippert ${ }^{2}$, E. Schleußner ${ }^{1}$, P. Hillemanns ${ }^{2}$, T. Lehmann ${ }^{3}$, F. von Versen-Höynck ${ }^{2}$

Abteilung für Geburtshilfe, Universitätsklinikum Jena, Jena, Germany

${ }^{2}$ Abteilung für Frauenheilkunde und Geburtshilfe, Medizinische Hochschule Hannover, Hannover, Germany

${ }^{3}$ Institut für Medizinische Statistik, Informatik und Dokumentation, Universitätsklinikum Jena, Jena, Germany
Key words

- gestational diabetes

- S3 guideline

- diagnosis

- treatment

- knowledge

\section{Schlüsselwörter}

- Gestationsdiabetes

- S3-Leitlinie

- Diagnostik

- Behandlung

- Kenntnis

Deutsche Version unter: http://dx.doi.org/ $10.1055 / \mathrm{s}-0042-109396$ received 13.10 .2015

accepted 29.5.2016

Bibliography

Dol http://dx.doi.org/ 10.1055/s-0042-109396

Geburtsh Frauenheilk 2016; 76: 771-778 @ Georg Thieme

Verlag KG Stuttgart · New York ISSN 0016-5751

\section{Correspondence \\ Dr. Tanja Groten}

Universitätsklinikum Jena

Klinik für Frauenheilkunde

und Geburtshilfe

Bachstraße 18

07743 Jena

Germany

tanja.groten@med.uni-jena.de

\section{Abstract}

$\nabla$

Background: An S3 guideline on the diagnosis and differentiated management of gestational diabetes (GDM) was published in Germany in 2011. This guideline replaced the previously applicable recommendations for the diagnosis and treatment of GDM and, for the first time, compiled evidence-based recommendations for the care of patients with GDM. The new guideline has focused particularly on the counselling offered to all patients with GDM about the associated long-term health risks. In this study we investigated the state of knowledge about the guideline among gynecologists and diabetologists in Thuringia and Lower Saxony.

Method: A questionnaire with 23 questions was sent out to 773 gynecologists and 76 diabetologists providing outpatient care in Lower Saxony and Thuringia. The statistical analysis was descriptive and inferential for comparisons between groups.

Results: The response rate was 54\%; an average of $47.6 \%$ of the individual questions were answered correctly in the completed questionnaires. The questions were answered correctly significantly more frequently by persons in the group with a good knowledge of the guidelines (75 vs. $61 \%$, $\mathrm{p}<0.001)$. There were no significant differences between groups when differences between federal states or medical specialties were compared. Conclusions: The results of our study show a good general state of knowledge of the guideline and point to a high level of willingness to implement the recommendations of the S3 guideline on GDM. With regard to the follow-up care provided to patients with GDM and depression, this study found a significant need for further training.

\section{Zusammenfassung \\ $\nabla$}

Hintergrund: In Deutschland wurde 2011 eine S3-Leitlinie zur Diagnostik und differenzierten Therapie des Gestationsdiabetes (GDM) publiziert. Die Leitlinie ersetzte die bis dahin geltenden Empfehlungen zur Diagnostik und Therapie des GDM und formuliert erstmals evidenzbasierte Empfehlungen zur Betreuung von Patientinnen mit GDM. Ein Schwerpunkt der Leitlinie ist die Beratung aller Patientinnen mit GDM über assoziierte gesundheitliche Langzeitrisiken. In der vorliegenden Studie haben wir fragebogengestützt den Kenntnisstand zum Inhalt der Leitlinien bei Gynäkologen und Diabetologen in Thüringen und Niedersachsen untersucht.

Methode: Ein Fragebogen mit 23 Fragen wurde an 773 Gynäkologen und 76 Diabetologen, die in der ambulanten Patientenversorgung in Niedersachsen und Thüringen tätig sind, geschickt. Die statistische Analyse erfolgte deskriptiv und inferenziell im Gruppenvergleich.

Ergebnisse: Bei einer Rücklaufquote von 54\% wurden durchschnittlich 47,6\% der Einzelfragen richtig beantwortet. Signifikant häufiger wurden Fragen in der Gruppe der Teilnehmer mit guter Leitlinienkenntnis richtig erwidert (75 vs. 61\%, $\mathrm{p}<0,001$ ). Im Gruppenvergleich nach Bundesland oder Fachrichtung ergab sich dagegen kein gravierender Unterschied.

Schlussfolgerungen: Die vorliegenden Ergebnisse dokumentieren einen guten Kenntnisstand zum Inhalt der Leitlinie und lassen auf eine weite Verbreitung sowie eine hohe Umsetzungsbereitschaft der S3-Leitlinie zum GDM schließen. Im Bereich der Nachsorge auf depressive Erkrankungen von Patientinnen mit GDM zeigt die vorliegende Umfrage deutlichen Fortbildungsbedarf auf.

\footnotetext{
* Shared first authorship
} 


\section{Introduction}

$\nabla$

According to a survey by the BQS (Institute for Quality \& Patient Safety), the prevalence of gestational diabetes (GDM) has more than doubled between 2002 (1.5\%) and 2010 (3.7\%) and is currently around $4.4 \%$ for all of Germany [1]. This means that almost 30000 pregnant women in Germany are affected annually.

If left untreated, maternal GDM leads to an oversupply of glucose to the fetus which can lead to the development of fetal hyperinsulinism. The consequences include fetal macrosomia, delayed surfactant production in the lungs and structural organ immaturity with regard to gestational age. Postnatally, these children present with typical diabetes-related complications such as respiratory adjustment disorders, hypoglycemia and hyperbilirubinemia. The extent of these disorders is correlated to the insulin concentrations in umbilical cord blood [2]. Moreover, maternal GDM can lead to abnormalities in fetal islet cell development and in the regulation of satiety. Children whose mothers had GDM are at increased risk of glucose tolerance disorders and obesity for the rest of their lives [3-5]. International studies such as the HAPO study showed a linear correlation between maternal blood glucose levels and the incidence of neonatal and maternal obstetric complications [6]. If maternal blood sugar levels are rigorously controlled and kept within normal ranges, the obstetric complications do not materialize, and nor do the perinatal and lifelong consequences for the children [7].

Epidemiological data on GDM additionally show an increased risk of maternal morbidity after GDM. Compared to pregnant women without glucose tolerance disorders, women after GDM have a 7 to 10 -fold higher risk of developing diabetes mellitus type 2 later on [8]. Moreover, patients who have glucose tolerance disorders in pregnancy have 1.7-fold higher risk of developing cardiovascular disease in later life and a 2 to 5 -fold higher risk of developing a metabolic co-morbidity (obesity, pulmonary arterial hypertension, dyslipoproteinemia) [9]. Epidemiological data have also shown that up to $35 \%$ of women who had GDM go on to develop depression or already suffer from it [12].

For children, early diagnosis and effective treatment of maternal GDM to prevent intrauterine oversupply of glucose with all the consequences described above represents an effective means of avoiding the long and short-term effects of intrauterine hyperinsulinism. For mothers with GDM, detailed information about the associated health risks, rigorous follow-up of maternal glucose tolerance and the inclusion of the patients in a preventive healthcare program will result in a significant improvement in long-term health $[10,11]$. The S3 guideline "Gestational Diabetes Mellitus, Diagnosis, Treatment and Follow-up" was developed in 2011 in cooperation with the German Diabetes Society and the German Society for Gynecology and Obstetrics. Medical guidelines are systematically developed aids to decision-making about the appropriate approach for particular health problems [17]. With the publication of the guideline in 2011, for the first time an evidence-based guideline was available on the care for patients with GDM in Germany [19]. The new guideline replaced the previous recommendations on the diagnosis and treatment of GDM dating from 2001. The recommendations formulated in the new guideline on the rigorous follow-up of patients with GDM represent an important expansion of the recommendations on the care of patients with GDM. The new guideline aims to optimize diagnostic accuracy and improve the care and particularly the follow-up of patients with GDM and their children. If the measures proposed in the guideline are to be effective, the guide- line would need to be widely disseminated, and its recommendations would need to be known to and implemented by attending physicians.

The aim of this study was to evaluate the diagnosis, treatment and follow-up provided to women with GDM by non-hospitalbased gynecologists and diabetologists four years after the publication of the new guideline and to assess the physicians' own knowledge of the guideline. To this end, we carried out an extensive questionnaire-based survey of diabetologists and gynecologists in Lower Saxony and Thuringia. The results showed the state of knowledge about the contents of the guideline and offered useful insights which will be used to improve the wording of the recommendations when the guideline is updated in 2017.

\section{Method \\ $\nabla$}

\section{Study and questionnaire design}

The questionnaire consisted of seven sets of questions with a total of 23 questions and was developed by two gynecologists who actively treat pregnant women with GDM. Under a number of headings, the questionnaire systematically surveyed the knowledge of the physician completing the questionnaire about the recommendations in the guideline on the "Diagnosis, Treatment and Counselling of Women with Gestational Diabetes". In addition, the questionnaire included fake questions on long-term risks such as malignancy, allergies and varicose veins, which have no relationship with gestational diabetes. The responses were obtained using scaled questions, where the responder could select an answer on a 4-point Likert scale ("strongly agree", "agree", "disagree", "strongly disagree"). After receiving the approval of the Ethics Committees of the Medical University of Hanover and of Jena University Hospital, the study was carried out in Lower Saxony and Thuringia between October 2013 and November 2014.

The first set of questions focused on the demographic data of respondents (years of professional experience working as a specialist, age range of patients treated in the respective doctor's office, percentage of patients who had previously given birth to at least one child). The next set of questions investigated whether the respondents followed the recommended screening procedures in the guideline [19] with regard to familial risk, and medical, prior, and current obstetric risk factors for developing GDM when examining and interviewing patients. The third set of questions looked at the respondents' approach to screening high-risk patients prior to the 24th week of gestation and the implementation of generalized screening between the 24th and 28th week of gestation using either the $75 \mathrm{~g}$ oral glucose tolerance test (oGTT) or the $50 \mathrm{~g}$ challenge test. The next set of questions evaluated the respondents' knowledge of the risks facing mother and child after a diagnosis of GDM, including long-term maternal risks and the acute and long-term consequences for the child if diabetes is not controlled during pregnancy. Another set of questions confronted respondents with questions about the counselling they provided after making a diagnosis and post partum. In the final set of questions, the respondents were asked to evaluate their own state of knowledge respecting the current GDM guideline [19] and the guideline on the treatment of neonates born to diabetic mothers [20]. 
Table 1 Demographic data.

\begin{tabular}{|c|c|c|c|}
\hline & $\begin{array}{l}\text { Gynecologists } \\
(\mathrm{n}=418)\end{array}$ & $\begin{array}{l}\text { Diabetologists } \\
(n=42)\end{array}$ & p-value* \\
\hline Response rate (dispatched questionnaires) & $54.1 \%$ (418 von 773$)$ & $55.3 \%$ ( 42 von 76$)$ & \\
\hline - male colleagues & $40.1 \%$ (108 von 269$)$ & $53.8 \%$ ( 28 von 52$)$ & \\
\hline - female colleagues & $61.6 \%$ (310 von 504$)$ & $58.3 \%$ (14 von 24$)$ & \\
\hline Distribution between the sexes & & & $<0.001$ \\
\hline$\checkmark$ male & $108(25.8 \%)$ & $28(66.7 \%)$ & \\
\hline female & $310(74.2 \%)$ & $14(33.3 \%)$ & \\
\hline Years of working as a medical specialist & & & 0.71 \\
\hline$><5$ years & $24(5.8 \%)$ & $0(0 \%)$ & \\
\hline - $5-10$ years & $72(17.4 \%)$ & $7(16.7 \%)$ & \\
\hline - $11-12$ years & $142(34.4 \%)$ & $18(42.9 \%)$ & \\
\hline$>>20$ years & $175(42.4 \%)$ & $17(40.5 \%)$ & \\
\hline Patient age & & & $<0.001$ \\
\hline - 20-40 years & $172(43.7 \%)$ & $6(15.0 \%)$ & \\
\hline - 45-50 years & $208(52.8 \%)$ & $6(15.0 \%)$ & \\
\hline$>>50$ years & $14(3.6 \%)$ & $28(70.0 \%)$ & \\
\hline Percentage of patients who had given birth to at least one child previously & & & 0.92 \\
\hline$><20 \%$ & $10(2.5 \%)$ & $5(15.2 \%)$ & \\
\hline - $20-40 \%$ & $116(29.3 \%)$ & $7(21.2 \%)$ & \\
\hline > $40-60 \%$ & $162(40.9 \%)$ & $8(24.2 \%)$ & \\
\hline$>>60 \%$ & $108(27.3 \%)$ & $13(39.4 \%)$ & \\
\hline Knowledge of the $\mathrm{S3}$ guideline on GDM & & & 0.08 \\
\hline - good & $236(57.4 \%)$ & $31(73.8 \%)$ & \\
\hline D fairly good & $158(38.4 \%)$ & $8(19.0 \%)$ & \\
\hline - fairly poor & $13(3.2 \%)$ & $1(2.4 \%)$ & \\
\hline not familiar with the guideline & $4(1.0 \%)$ & $2(4.8 \%)$ & \\
\hline
\end{tabular}

\section{Study population}

The participants in the study were randomly selected from the publicly available database of physicians maintained by the Medical Associations of Lower Saxony and Thuringia; at the time of the survey the respondents were working as non-hospital-based gynecologists or diabetologists. 774 gynecologists were randomly selected out of a total of 1292 gynecologists listed in the database, and 76 diabetologists were selected out of a total of 286 listed diabetologists. The distribution between female and male participants ( $64.5 \%$ female) was comparable to that of the overall population in the database ( $65 \%$ female). A cover letter and a prepaid return envelope were sent out by mail together with the questionnaire. Physicians who had not responded after two months were sent a reminder letter. Answers were anonymized in the study center after the completed questionnaire had been returned.

\section{Statistical evaluation}

Statistical evaluation was descriptive, and included frequency, mean and standard deviation. Analysis was carried out using SPPS for Windows, Version 21 (SPSS Inc. Chicago, USA). Comparisons of groups of nominal items in the questionnaire was done by $\mathrm{X}^{2}$-test (all fields of the fourfold table $\geq 5$ ) or Fisher's exact test (one field $<5$ ). Differences in the number of correctly answered questions were analyzed by t-test for independent samples; data classified as demographic (e.g. years) were analyzed using MannWhitney U-test for differences between groups. Groups were grouped together if there was not much difference in the answers between the different groups (e.g. years of clinical experience: under 10 years and over 10 years). For statistical analysis, the answers "strongly agree" and "agree" were summarized as the respondent having a good knowledge of the guideline. A poor knowledge of the guideline was indicated by grouping together the answers "disagree" and "strongly disagree". The percentage of respondents with a good or a poor knowledge of the guideline were compared with respect to demographic data, professional characteristics, their approach to taking the patient's medical and familial history and to screening and counselling. Differences were considered significant when $\mathrm{p}$-values were $<0.05$.

\section{Results}

Descriptive data for the cohort of surveyed physicians $460(54.2 \%)$ out a total of 849 physicians who received the questionnaire returned a completed questionnaire; the figure was 418 (54.1\%) out of 774 for gynecologists and 42 (55.3\%) out of 76 for diabetologists. When the two groups were compared, gynecologists were more commonly women ( 74.2 vs. $33.3 \%$; $\mathrm{p}<0.001$ ) and cared for a younger patient population (women of child-bearing age 41.1 vs. $14.3 \%$; $p<0.001$ ) than the participating diabetologists. More than $90 \%$ of respondents considered that they had a good knowledge of the guideline. Additional descriptive data are summarized in $\odot$ Table 1.

\section{Overall evaluation of responses to the questionnaire}

Based on the recommendations in the guideline, possible answers to the set of questions 7 to 20 were divided into "corresponds with the guideline" and "does not correspond with the guideline" (Fig. S1, highlighted in green), and the possible answers "strongly agree" and "agree" were grouped together as "yes" while "disagree" and "strongly disagree" were grouped together as "no". A total of 64 individual questions were evaluated. An average of $47.6( \pm 5.5)$ questions were answered correctly. 
Table 2 Intergroup comparison of the results of the survey. Comparison between gynecologists and diabetologists (all results).

\begin{tabular}{|c|c|c|c|}
\hline & $\begin{array}{l}\text { Gynecologists } \\
\text { (max. } n=418 \text { ) }\end{array}$ & $\begin{array}{l}\text { Diabetologists } \\
\text { (max. } n=42 \text { ) }\end{array}$ & p-values \\
\hline Total number of correctly answered questions (mean for 64 ) & 47.6 & 47.5 & 0.97 \\
\hline \multicolumn{4}{|l|}{ Initial medical examination } \\
\hline - examined even non-pregnant women for diabetes & $85.7 \%(n=354)$ & $100.0 \%(n=40)$ & 0.005 \\
\hline - previous history of GDM in pregnant women & $99.8 \%(n=412)$ & $100.0 \%(n=42)$ & 1.00 \\
\hline - dyslipidemia & $69.6 \%(n=286)$ & $90.2 \%(n=37)$ & 0.004 \\
\hline - intake of contra-insulin medication & $93.5 \%(n=386)$ & $97.6 \%(n=41)$ & 0.50 \\
\hline obesity & $100.0 \%(n=412)$ & $100.0 \%(n=42)$ & - \\
\hline - familial history of diabetes & $98.5 \%(n=407)$ & $100.0 \%(n=40)$ & 1.00 \\
\hline - mother had GDM/own birth weight & $50.1 \%(n=207)$ & $57.1 \%(n=24)$ & 0.42 \\
\hline \multicolumn{4}{|l|}{ Knowledge of the risk factors for developing GDM } \\
\hline overweight & $97.8 \%(n=404)$ & $100.0 \%(n=41)$ & 1.000 \\
\hline - parents/siblings with diabetes & $98.8 \%(n=405)$ & $97.6 \%(n=40)$ & 0.44 \\
\hline - GDM in a previous pregnancy & $100.0 \%(n=413)$ & $100.0 \%(n=41)$ & - \\
\hline - s/p birth of a child $>4500 \mathrm{~g}$ & $99.3 \%(n=410)$ & $100.0 \%(n=41)$ & 1.00 \\
\hline s/p stillbirth & $75.4 \%(n=309)$ & $89.2 \%(n=33)$ & 0.07 \\
\hline - tendency to recurrent miscarriage & $60.3 \%(n=246)$ & $89.5 \%(n=34)$ & $<0.001$ \\
\hline - serious congenital malformations in previous pregnancies & $54.3 \%(n=221)$ & $86.5 \%(n=32)$ & $<0.001$ \\
\hline \multicolumn{4}{|l|}{ Screening (women with normal risk of diabetes) } \\
\hline - measurement of occasional plasma glucose (right answer: no) & $82.5 \%(n=254)$ & $55.2 \%(n=16)$ & $<0.001$ \\
\hline - measurement of fasting glucose levels (right answer: no) & $72.1 \%(n=225)$ & $30.0 \%(n=9)$ & $<0.001$ \\
\hline - measurement of glucose in urine (right answer: no) & $11.5 \%(n=39)$ & $58.6 \%(n=17)$ & $<0.001$ \\
\hline - $50 \mathrm{~g}$ challenge test & $95.3 \%(n=382)$ & $17.2 \%(n=5)$ & $<0.001$ \\
\hline - $75 \mathrm{~g}$ oral glucose tolerance test & $57.1 \%(n=190)$ & $97.3 \%(n=36)$ & $<0.001$ \\
\hline - no screening test (right answer: no) & $98.6 \%(n=292)$ & $79.3 \%(n=23)$ & $<0.001$ \\
\hline \multicolumn{4}{|l|}{ Screening (women with increased risk of diabetes) } \\
\hline - measurement of occasional plasma glucose & $36.2 \%(n=117)$ & $63.3 \%(n=19)$ & 0.004 \\
\hline - measurement of fasting glucose levels & $48.7 \%(n=164)$ & $77.4 \%(n=24)$ & 0.002 \\
\hline - measurement of glucose in urine (right answer: no) & $13.5 \%(n=47)$ & $53.6 \%(n=15)$ & $<0.001$ \\
\hline - $50 \mathrm{~g}$ challenge test (right answer: no) & $45.8 \%(n=159)$ & $82.1 \%(n=23)$ & $<0.001$ \\
\hline - $75 \mathrm{~g}$ oral glucose tolerance test & $52.3 \%(n=179)$ & $89.2 \%(n=33)$ & $<0.001$ \\
\hline \multicolumn{4}{|l|}{ Counselling and monitoring of patients diagnosed with GDM } \\
\hline - maternal consequences (first consultation) & $98.3 \%(n=404)$ & $92.1 \%(n=35)$ & 0.04 \\
\hline - breastfeeding (first consultation) & $63.7 \%(n=256)$ & $64.7 \%(n=22)$ & 0.91 \\
\hline - benefits of regular physical activity (first consultation) & $97.3 \%(n=399)$ & $97.5 \%(n=39)$ & 1.00 \\
\hline nutrition (first consultation) & $99.5 \%(n=408)$ & $100.0 \%(n=40)$ & 1.00 \\
\hline - risk of nicotine consumption (first consultation) & $85.0 \%(n=345)$ & $100.0 \%(n=39)$ & 0.005 \\
\hline - long-term consequences for the child (first consultation) & $99.5 \%(n=411)$ & $97.5 \%(n=39)$ & 0.24 \\
\hline - self-monitoring of blood glucose (first consultation) & $93.1 \%(n=380)$ & $100.0 \%(n=39)$ & 0.16 \\
\hline $\begin{array}{l}\text { recommended delivery in a perinatal center I/II for women with GDM managed through } \\
\text { diet }\end{array}$ & $63.0 \%(n=255)$ & $63.9 \%(n=23)$ & 0.91 \\
\hline $\begin{array}{l}\text { recommended delivery in a perinatal center I/II for women who need insulin to manage } \\
\text { their GDM }\end{array}$ & $92.9 \%(n=379)$ & $97.4 \%(n=38)$ & 0.50 \\
\hline - routine counselling on how to reduce cardiac risk factors in patients aged $>50$ years & $70.0 \%(n=282)$ & $92.7 \%(n=38)$ & 0.002 \\
\hline - routine counselling on how to reduce cardiac risk factors in patients s/p GDM & $70.9 \%(n=288)$ & $85.4 \%(n=35)$ & 0.049 \\
\hline - routine counselling on how to reduce cardiac risk factors in patients s/p pre-eclampsia & $71.9 \%(n=291)$ & $69.2 \%(n=27)$ & 0.73 \\
\hline \multicolumn{4}{|l|}{ Knowledge of the risks and long-term consequences of GDM for the child } \\
\hline prematurity & $81.9 \%(n=322)$ & $100.0 \%(n=40)$ & 0.001 \\
\hline - macrosomia & $99.5 \%(n=407)$ & $100.0 \%(n=41)$ & 1.00 \\
\hline hyperbilirubinemia & $72.1 \%(n=282)$ & $89.2 \%(n=33)$ & 0.03 \\
\hline D surfactant production disorder & $76.2 \%(n=298)$ & $80.6 \%(n=29)$ & 0.56 \\
\hline - increased risk of becoming overweight in later life & $98.0 \%(n=399)$ & $97.5 \%(n=39)$ & 0.57 \\
\hline increased risk of hypertension in later life & $85.1 \%(n=338)$ & $82.4 \%(n=28)$ & 0.66 \\
\hline - increased risk of diabetes mellitus type 2 in later life & $96.8 \%(n=395)$ & $97.6 \%(n=40)$ & 1.00 \\
\hline - false statement: hyperglycemia post partum & $45.3 \%(n=180)$ & $62.9 \%(n=22)$ & 0.046 \\
\hline - false statement: increased risk of allergies & $66.4 \%(n=253)$ & $83.9 \%(n=26)$ & 0.045 \\
\hline - false statement: increased risk of malignancy & $66.6 \%(n=257)$ & $75.8 \%(n=25)$ & 0.28 \\
\hline \multicolumn{4}{|l|}{ Knowledge of the long-term consequences of GDM for the mother } \\
\hline - glucose tolerance disorders in subsequent pregnancies & $100.0 \%(n=411)$ & $100.0 \%(n=41)$ & - \\
\hline diabetes mellitus type 2 in later life & $98.3 \%(n=401)$ & $100.0 \%(n=41)$ & 1.00 \\
\hline - hypertension in later life & $81.7 \%(n=331)$ & $83.3 \%(n=30)$ & 0.81 \\
\hline - dyslipidemia in later life & $93.6 \%(n=378)$ & $86.1 \%(n=31)$ & 0.09 \\
\hline - false statement: increased risk of varicose veins & $77.3 \%(n=303)$ & $85.3 \%(n=29)$ & 0.28 \\
\hline
\end{tabular}


Table 2 Intergroup comparison of the results of the survey. Comparison between gynecologists and diabetologists (all results). (Continued)

\begin{tabular}{|c|c|c|c|}
\hline & $\begin{array}{l}\text { Gynecologists } \\
\text { (max. } n=418 \text { ) }\end{array}$ & $\begin{array}{l}\text { Diabetologists } \\
\text { (max. } n=42 \text { ) }\end{array}$ & p-values \\
\hline \multicolumn{4}{|l|}{ State of knowledge on follow-up care } \\
\hline - $75 \mathrm{~g} \mathrm{oGTT}$ post partum & $84.3 \%(n=337)$ & $95.1 \%(n=39)$ & 0.07 \\
\hline - testing for diabetes every $2-3$ years if oGTT post partum is normal & $78.6 \%(n=313)$ & $95.0 \%(n=38)$ & 0.01 \\
\hline - annual testing for diabetes if oGTT post partum is abnormal & $80.9 \%(n=321)$ & $92.1 \%(n=35)$ & 0.12 \\
\hline - metabolically neutral contraception & $82.3 \%(n=331)$ & $70.3 \%(n=26)$ & 0.07 \\
\hline - counselling about increased cardiovascular risk & $85.2 \%(n=346)$ & $77.8 \%(n=28)$ & 0.24 \\
\hline - counselling on increased risk of developing diabetes mellitus type 2 & $98.3 \%(n=402)$ & $100.0 \%(n=41)$ & 1.00 \\
\hline - assessment for postpartum depression & $22.0 \%(n=87)$ & $24.3 \%(n=9)$ & 0.75 \\
\hline \multicolumn{4}{|l|}{ Familiarity with guidelines and interest in further training } \\
\hline - guideline on the care of diabetic mothers & $42.6 \%(n=175)$ & $42.9 \%(n=18)$ & 0.97 \\
\hline - GDM guideline very useful for clinical practice & $87.7 \%(n=357)$ & $97.4 \%(n=38)$ & 0.11 \\
\hline - interested in further training & $91.3 \%(n=376)$ & $97.6 \%(n=41)$ & 0.23 \\
\hline
\end{tabular}

\section{Comparative analysis of responses from gynecologists and diabetologists}

In both groups, an average of 47 out of 64 questions were answered correctly; only a few individual questions showed significant deviations ( $\odot$ Table 2). Diabetologists, for example, reported significantly more often that they evaluated even non-pregnant patients for diabetes during the general medical examination (100.0 vs. $85.7 \% ; p=0.005)$, and diabetologists were also more likely to test pregnant patients for dyslipidemia (90.2 vs. $69.6 \%$; $\mathrm{p}=0.004)(\odot$ Table 2$)$.

More than $95 \%$ of respondents in both groups showed a good knowledge of the risk factors described in the guideline. Diabetologists significantly more often knew about specific obstetric risk factors such as propensity for recurrent miscarriage (89.5 vs. $60.3 \% ; \mathrm{p} \leq 0.001$ ) and a prior history of serious congenital malformations ( 86.5 vs. $54.3 \%$; $\leq \leq 0.001$ ) (O Table 2).

The guideline describes a number of different approaches to examine pregnant women for GDM. For patients at risk, the guideline recommends following a step-by-step scheme when examining patients for GDM. The guideline recommends that a $75 \mathrm{~g}$ oGTT is done between $24+0$ and $27+6$ weeks of gestation in all pregnant women with no increased risk for GDM. The guideline considers a two-stage approach, starting with a $50 \mathrm{~g}$ glucose challenge test (GCT), to be acceptable as long as the test and its interpretation are done correctly, but this approach is not explicitly recommended. The answers of the surveyed study population about the methods used to diagnose GDM varied greatly (๑ Table 2). Overall, we found no uniform approach, nor did either of the medical specialties use a specific approach to diagnose GDM. Contrary to the recommendations, $54.2 \%$ of gynecologists and $17.9 \%$ of diabetologists $(p<0.001)$ carried out a 50 g glucose challenge test in patients at increased risk of GDM. Based on the recommendations of the guideline, diabetologists were more likely $(89.2$ vs. $52.3 \% ; \mathrm{p}<0.001)$ to carry out the $75 \mathrm{~g}$ oGTT as the primary diagnostic test in patients at risk (० Table 2 ).

Doctors' knowledge of the topics which the guideline recommends to address during the first meeting with a patient was high in both specialist groups and barely differed between the groups. Gynecologists significantly less often included the risk of nicotine consumption in their talk with a patient after making the diagnosis ( 85.0 vs. $100.0 \%$; $p=0.005$ ). Only $63.7 \%$ of gynecologists and $64.7 \%$ of diabetologists $(\mathrm{p}=0.91)$ talked to their patients about the importance of breastfeeding for GDM during their first meeting with the patient (@ Table 2).
Overall, knowledge of the long-term effects on children was good. However, only $43.3 \%$ of gynecologists and $62.9 \%$ of diabetologists gave the right answer of "no" $(\mathrm{p}=0.046)$ in response to the false statement: "postpartum hyperglycemia represents a risk for the child"; $77.3 \%$ of gynecologists and $85.3 \%$ of diabetologists $(\mathrm{p}=0.281)$ answered correctly with respect to the increased risk of varicose veins for the mother. More than $95 \%$ of the respondents were aware of the increased risk of the mother developing type 2 diabetes and hypertension after GDM. Only 22.0 and $24.3 \%$ respectively $(\mathrm{p}=0.748)$ examined the patient for postpartum depression (O Table 2 ).

\section{Comparative analysis on the level of knowledge}

of the guidelines in the respective federal states

Although overall, the level of knowledge respecting the guidelines was good, a comparison of the two federal states highlighted some differences between the two states. The patients of colleagues working in Thuringia were older $(\mathrm{p}=0.014)$ and a higher percentage of them had previously given birth to at least one child $(p=0.005)$ (data not shown). Physicians in Lower Saxony listed $\mathrm{s} / \mathrm{p}$ stillbirth of a child $(\mathrm{p}=0.001)$ and tendency to recurrent miscarriage $(p<0.001)$ significantly more often as risks for developing GDM. Colleagues practicing in Lower Saxony knew about the increased risk of postnatal hyperbilirubinemia $(p=0.01)$ and of disorders of surfactant production $(p<0.001)$ in neonates significantly more often. Physicians practicing in Thuringia affirmed the increased risk of diabetes for the child significantly more often $(\mathrm{p}=0.003)$ and counselled women on their increased risk of developing cardiovascular disease more often $(\mathrm{p}=0.03)(\mathbf{O}$ Table 3$)$.

\section{Familiarity with the guideline}

Physicians who reported that they were familiar with the guideline answered correctly more often. The average number of questions answered correctly differed significantly between groups (47.9 vs. 39.8; $\mathrm{p}=0.009$ ). Questions which focused specifically on newly formulated recommendations in the S3 guideline were answered correctly significantly more often by physicians familiar with the guideline. At the initial medical examination of the patient, physicians familiar with the guideline were more likely to ask pregnant patients whether their mothers had had GDM and to inquire about the patients' own birth weight $(\mathrm{p}=0.009)$, and to inform patients during the first meeting after making a diagnosis about the importance of breastfeeding $(p=0.046)$ and 
Table 3 Intergroup comparison of results. Comparison between the two federal states (only significant results shown).

\begin{tabular}{|c|c|c|c|}
\hline & $\begin{array}{l}\text { Lower Saxony } \\
\text { (max. } n=304 \text { ) }\end{array}$ & $\begin{array}{l}\text { Thuringia } \\
\text { (max. } n=156 \text { ) }\end{array}$ & p-value \\
\hline Total number of questions answered correctly (mean of 64) & 47.8 & 47.2 & 0.30 \\
\hline \multicolumn{4}{|l|}{ Knowledge of the risk factors for developing GDM } \\
\hline s/p stillbirth & $81.1 \%(n=240)$ & $67.5 \%(n=102)$ & 0.001 \\
\hline - tendency to recurrent miscarriage & $68.5 \%(n=203)$ & $51.0 \%(n=77)$ & $<0.001$ \\
\hline \multicolumn{4}{|l|}{ Knowledge of the risks and long-term consequences of GDM for the child } \\
\hline - hyperbilirubinemia & $77.4 \%(n=223)$ & $65.7 \%(n=92)$ & 0.01 \\
\hline - surfactant production disorder & $84.6 \%(n=241)$ & $60.6 \%(n=86)$ & $<0.001$ \\
\hline - false statement: hyperglycemia post partum & $53.8 \%(n=155)$ & $32.6 \%(n=47)$ & $<0.001$ \\
\hline increased risk of diabetes mellitus type 2 later on & $95.3 \%(n=283)$ & $100.0 \%(n=152)$ & 0.003 \\
\hline \multicolumn{4}{|l|}{ Follow-up } \\
\hline - counselling about the increased risk of cardiovascular disease & $81.9 \%(n=240)$ & $89.9 \%(n=134)$ & 0.03 \\
\hline
\end{tabular}

Table 4 Intergroup comparison of the results of the survey. Familiarity with the current guidelines.

\begin{tabular}{|c|c|c|c|}
\hline & Yes (max. $n=433)$ & No $(\max . n=20)$ & p-value \\
\hline Total number of questions answered correctly (mean of 64) & 47.9 & 39.8 & $<0.001$ \\
\hline \multicolumn{4}{|l|}{ Initial medical examination and interview } \\
\hline - patient questioned about mother's pregnancy when the patient herself was born & $52.2 \%(n=226)$ & $21.1 \%(n=4)$ & 0.009 \\
\hline \multicolumn{4}{|l|}{ Screening (women with normal risk of diabetes) } \\
\hline - $50 \mathrm{~g}$ challenge test (normal risk) & $91.0 \%(n=373)$ & $64.7 \%(n=11)$ & $<0.001$ \\
\hline \multicolumn{4}{|l|}{ Screening (women with increased risk of diabetes) } \\
\hline - measurement of fasting glucose levels (increased risk) & $52.1 \%(n=182)$ & $23.5 \%(n=4)$ & 0.03 \\
\hline \multicolumn{4}{|l|}{ Counselling and monitoring of women diagnosed with GDM } \\
\hline - breastfeeding (initial meeting) & $64.9 \%(n=270)$ & $41.2 \%(n=7)$ & 0.046 \\
\hline - benefits of regular physical activity & $98.1 \%(n=422)$ & $77.8 \%(n=14)$ & 0.001 \\
\hline \multicolumn{4}{|l|}{ Knowledge of the risks and long-term consequences of GDM for the child } \\
\hline prematurity & $84.3 \%(n=349)$ & $64.7 \%(n=11)$ & 0.03 \\
\hline \multicolumn{4}{|l|}{ Knowledge about follow-up care } \\
\hline - routine counselling to reduce risk factors for cardiac disease if the patient is s/p GDM & $73.0 \%(n=311)$ & $50.0 \%(n=9)$ & 0.03 \\
\hline - routine counselling to reduce risk factors for cardiac disease if the patient is $>50$ years old & $73.1 \%(n=310)$ & $47.1 \%(n=8)$ & 0.02 \\
\hline $\begin{array}{l}\text { routine counselling to reduce risk factors for cardiac disease if the patient is } \mathrm{s} / \mathrm{p} \\
\text { pre-eclampsia }\end{array}$ & $72.6 \%(n=307)$ & $50.0 \%(n=9)$ & 0.03 \\
\hline $75 \mathrm{~g}$ oGTT postpartum & $86.0 \%(n=361)$ & $66.7 \%(n=12)$ & 0.03 \\
\hline - check-up every 2-3 years to test for diabetes if the postpartum oGTT result is normal & $80.8 \%(n=337)$ & $61.1 \%(n=11)$ & 0.04 \\
\hline - annual check-up to test for diabetes if the postpartum oGTT result is abnormal & $82.9 \%(n=343)$ & $55.6 \%(n=10)$ & 0.003 \\
\hline counselling about the increased risk of developing diabetes mellitus type 2 & $98.8 \%(n=424)$ & $88.9 \%(n=16)$ & 0.03 \\
\hline
\end{tabular}

the benefits of regular physical activity $(p=0.001)$. Similarly, physicians familiar with the guideline informed patients more often about the increased risk after GDM of developing cardiovascular disease in later life ( $p=0.037)$, about the necessity of carrying out a $75 \mathrm{~g}$ oGTT postpartum $(\mathrm{p}=0.027)$, about the importance of an annual follow-up to monitor for diabetes if the results of the postpartum $75 \mathrm{~g}$ oGTT were abnormal $(\mathrm{p}=0.003)$, and about the importance of being checked for diabetes every 2-3 years even if the results of the postpartum test were normal $(p=0.041)(-$ Table 4). Likewise, this group of physicians offered counselling on metabollically neutral contraception $(p=0.013)$, the increased risk of cardiovascular disease $(p=0.041)$ and diabetes $(p=0.029)$ significantly more often (data not shown). The majority of gynecologists (85.4\%) and diabetologists (90.4\%) considered the guideline to be helpful for general practice.

\section{Discussion \\ $\nabla$}

The results of our questionnaire-based survey presented here on the knowledge and implementation of the recommendations of the S3 guideline published at the end of 2011 on the diagnosis, treatment and follow-up of GDM showed a clear correlation between a good knowledge of the guideline (self-assessment) and the implementation of the recommendations of the guideline on the care of pregnant women. A correlation between the implementation of recommendations of the guideline and the federal state (Thuringia or Lower Saxony) or medical specialty (gynecology/obstetrics or diabetology) was only found for a few individual questions. Overall, more than $90 \%$ of respondents claimed to have a good knowledge of the guideline. A survey published in 2005 on the application of guidelines by Berlin family doctors found that only $40 \%$ of assessed physicians were familiar with guidelines and implemented their recommendations [13]. Even if questionnaire-based surveys have the fundamental weakness that they generate socially desirable answers, knowledge of the guideline - which was reported as $90 \%$ - shows that the guide- 
line on GDM is well known and generally accepted. The response rate of $54 \%$ shows the great importance which respondents attached to the guideline. In an analysis of published studies based on questionnaires sent by post, Anseel et al. found an average response rate of $41 \%$. With a rate of $54 \%$, the response rate for our study places our study in the top third of this comparison [14]. The rules of the AWMF [15] recommend that the wording of recommendations in guidelines must show the level of evidence and importance. A strong recommendation (evidence level A) is expressed by the words "must/must not"; a simple recommendation (evidence level B) is indicated by the words "should/should not", while an open recommendation is expressed by the words "can/cannot". In the most current version of the guideline, there are no recommendations for the topics Screening and Diagnostic Approach for Pregnant Women at Risk which used the words "should"|"should not" or "can"/"cannot". This is due to the fact that at the time when the guideline was being compiled in 2011, the discussion about the introduction of mandatory testing for GDM in the maternity policy guidelines had not yet ended. The authors therefore gave a comprehensive and neutral overview of the existing literature but abstained from making explicit recommendations. This background explains the heterogeneous results with regard to the set of questions on screening and diagnostic approaches. In an online survey Nast et al. investigated the perceived binding nature of recommendations depending on the wording [16]. The authors came to the conclusion that terms such as "should", "must" and "must not" were perceived as binding, but found it more difficult to discriminate between "should" and "can". The results of our study could contribute to formulating clear and unambiguous recommendations for Screening and Diagnosis in the forthcoming 2016 revision of the guideline.

However with regard to Follow-up Care after GDM, the guideline formulated clear, evidence-based, unambiguous "SHOULD" recommendations. This was one area, in particular, where our study showed highly significant differences in the knowledge of the guideline's recommendations between the respondents who had a good knowledge of the guideline and those who did not, whereas there were no significant differences between medical specialties or federal state.

With regard to follow-up care, the study clearly showed that the risk of postpartum depression after GDM is not widely known. Only $20 \%$ of respondents examined their patients for depression. The recommendation in the guideline proposes that evaluation of the risk for depression should be done when the patient presents to the doctor's office for her postpartum oGTT. But the follow-up rate of women after GDM is only $30 \%$ [18]. As up to one third of women go on to develop depression after GDM [12], the implementation of this recommendation would appear to be inadequate, and examination should perhaps also be carried out at a later point in time. This is an area where more training is necessary, particularly in view of the fact that more than $90 \%$ of gynecologists and $70 \%$ of diabetologists stated that they would be interested in further training on GDM.

To monitor the quality of guideline implementation, the AWMF has proposed setting up quality targets to investigate the quality of results. The guideline on GDM states in this context: "It is recommended that the quality of GDM therapy be checked at regular intervals based on the prevalence of morbidities reported in the HAPO study. The goal is to lower the prevalence of morbidities by the year 2020 until prevalences are approximately equal to those of the 'No GDM' group." What this means is that the extent to which the guideline is implemented must be measured by the extent to which the incidence of GDM-related complications during pregnancy and in neonates approaches that of healthy controls. A diagnosis of GDM in itself would then no longer be associated with increased peripartum and perinatal morbidity. This goal can only be achieved in the longer term if the recommendations given in the evidence-based guideline are complied with, and can only be managed with the close cooperation of diabetologists, gynecologists, pediatricians, diabetes advisors and midwives. The results of the present study show that a well-drafted S3 guideline can make a significant contribution towards achieving this goal.

\section{Conclusions for Clinical Practice \\ $\nabla$}

The overall knowledge of gynecologists and diabetologists in Thuringia and Lower Saxony regarding the contents of the S3 guideline on gestational diabetes is very good and shows a good implementation of the guideline's recommendations. Irrespective of the medical specialty or federal state, self-assessments that the respondent had a "good knowledge of the guideline" were found to be significantly correlated with care of patients with GDM being commensurate with the recommendations in the guideline. Particularly with regard to the follow-up care of women after pregnancy, better care was found to be correlated with a better knowledge of the guideline. All of the respondents showed gaps in their knowledge with regard to the increased risk of patients with GDM for developing depression and with regard to the importance of breastfeeding for GDM.

\section{Conflict of Interest}

\section{$\nabla$}

None.

\section{References}

1 Institut A. AQUA: Bundesauswertung zum Erfassungsjahr 2013-16/1 Geburtshilfe. AQUA Institut für angewandte Qualitätsförderung und Forschung im Gesundheitswesen; 2013

2 Metzger BE, Lowe LP, Dyer AR et al. Hyperglycemia and adverse pregnancy outcomes. N Engl J Med 2008; 358: 1991-2002

3 Clausen TD, Mathiesen ER, Hansen T et al. High prevalence of type 2 diabetes and pre-diabetes in adult offspring of women with gestational diabetes mellitus or type 1 diabetes: the role of intrauterine hyperglycemia. Diabetes Care 2008; 31: 340-346

4 Hunger-Dathe W, Mosebach N, Sämann A et al. Prävalenz einer Glukosetoleranzstörung und Adipositas von Kindern im Alter von 6 Jahren nach Gestationsdiabetes der Mutter in der Indexgravidität. Geburtsh Frauenheilk 2005; 65: 942-949

5 Plagemann A, Harder T, Kohlhoff $R$ et al. Overweight and obesity in infants of mothers with long-term insulin-dependent diabetes or gestational diabetes. Int J Obes Relat Metab Disord 1997; 21: 451-456

6 HAPO Study Cooperative Research Group; Metzger BE, Lowe LP, Dyer AR et al. Hyperglycemia and adverse pregnancy outcomes. $\mathrm{N}$ Engl J Med 2008; 358: 1991-2002

7 Han S, Crowther CA, Middleton P. Interventions for pregnant women with hyperglycaemia not meeting gestational diabetes and type 2 diabetes diagnostic criteria. Cochrane Database Syst Rev 2012; 1 : CD009037

8 Bellamy L, Casas JP, Hingorani AD et al. Type 2 diabetes mellitus after gestational diabetes: a systematic review and meta-analysis. Lancet 2009; 373: 1773-1779

9 Verier-Mine 0 . Outcomes in women with a history of gestational diabetes. Screening and prevention of type 2 diabetes. Literature review. Diabetes Metab 2010; 36: 595-616

10 Asif $M$. The prevention and control the type- 2 diabetes by changing lifestyle and dietary pattern. J Educ Health Promot 2014; 3: 1 
11 Ehrenthal DB, Catov JM. Importance of engaging obstetrician/gynecologists in cardiovascular disease prevention. Curr Opin Cardiol 2013; 28: 547-553

12 Nicklas JM, Miller LJ, Zera CA et al. Factors associated with depressive symptoms in the early postpartum period among women with recent gestational diabetes mellitus. Matern Child Health J 2013; 17: 16651672

13 Kunz A, Gusy B. Leitlinien in der Medizin: Anwendung, Einstellungen, Barrieren. Eine Befragung Berliner Hausärzte. Gesundheitswesen 2005; 67 - VF_V32

14 Anseel F, Lievens F, Schollaert E et al. Response rates in organizational science, 1995-2008: a meta-analytic review and guidelines for survey researchers. J Bus Psychol 2010; 25: 335-349

15 Arbeitsgemeinschaft der Wissenschaftlichen Medizinischen Fachgesellschaften (AWMF) - Ständige Kommission Leitlinien. AWMF-Regelwerk „Leitlinien“. 1. Aufl. 2012. Online: http://www.awmf.org/leitlinien/ awmf-regelwerk.html; last access: 06.01.2016

16 Nast A, Sporbeck B, Jacobs A et al. Wahrnehmung der Verbindlichkeit von Leitlinienempfehlungen. Study of perception of the extent to which guidelines recommendations are binding a survey of commonly used terminology. Dtsch Arztebl Int 2013; 110: 663-668
17 Bloch RE, Lauterbach K, Oesingmann U et al. Bekanntmachungen: Beurteilungskriterien für Leitlinien in der medizinischen Versorgung Beschlüsse der Vorstände von Bundesärztekammer und Kassenärztlicher Bundesvereinigung, Juni 1997. Dtsch Arztebl 1997; 94: A-2154/B$1831 / C-635$

18 Carmody L, Egan AM, Dunne FP. Postpartum glucose testing for women with gestational diabetes mellitus: Improving regional recall rates. Diabetes Res Clin Pract 2015; 108: e38-e41

19 Kleinwechter H, Schäfer-Graf U, Bührer C et al. Gestationsdiabetes mellitus (GDM), Evidenzbasierte Leitlinie zu Diagnostik, Therapie und Nachsorge der Deutschen Diabetes-Gesellschaft (DDG) und der Deutschen Gesellschaft für Gynäkologie und Geburtshilfe (DGGG) 2011. Online: http://www.awmf.org/uploads/tx_szleitlinien/057-0081_S3_ Gestationsdiabetes_2011-08.pdf; last access: 03.03.2016

20 Betreuung von Neugeborenen diabetischer Mütter 2010. Online: http://www.awmf.org/uploads/tx_szleitlinien/024-006_S2k_IDA_ Betreuung_von_Neugeborenen_diabetischer_Muetter_2010abgelaufen.pdf; last access: 03.03.2016 